\title{
Metarhodopsin control by arrestin, light-filtering screening pigments, and visual pigment turnover in invertebrate microvillar photoreceptors
}

\author{
Doekele G. Stavenga $\cdot$ Roger C. Hardie
}

Received: 27 August 2010/Revised: 29 September 2010/Accepted: 20 October 2010/Published online: 3 November 2010

(C) The Author(s) 2010. This article is published with open access at Springerlink.com

\begin{abstract}
The visual pigments of most invertebrate photoreceptors have two thermostable photo-interconvertible states, the ground state rhodopsin and photo-activated metarhodopsin, which triggers the phototransduction cascade until it binds arrestin. The ratio of the two states in photoequilibrium is determined by their absorbance spectra and the effective spectral distribution of illumination. Calculations indicate that metarhodopsin levels in fly photoreceptors are maintained below $\sim 35 \%$ in normal diurnal environments, due to the combination of a bluegreen rhodopsin, an orange-absorbing metarhodopsin and red transparent screening pigments. Slow metarhodopsin degradation and rhodopsin regeneration processes further subserve visual pigment maintenance. In most insect eyes, where the majority of photoreceptors have green-absorbing rhodopsins and blue-absorbing metarhodopsins, natural illuminants are predicted to create metarhodopsin levels greater than $60 \%$ at high intensities. However, fast metarhodopsin decay and rhodopsin regeneration also play an important role in controlling metarhodopsin in green receptors, resulting in a high rhodopsin content at low light intensities and a reduced overall visual pigment content in bright light. A simple model for the visual pigment-arrestin cycle is used to illustrate the dependence of the visual pigment population states on light intensity, arrestin levels and pigment turnover.
\end{abstract}

\footnotetext{
D. G. Stavenga $(\square)$

Department of Neurobiophysics, University of Groningen, Groningen, The Netherlands

e-mail: D.G.Stavenga@rug.nl

R. C. Hardie

Department of Physiology, Development and Neuroscience, University of Cambridge, Cambridge CB2 3DY, UK
}

Keywords Natural light · Light sensitivity · Pupil mechanism $\cdot$ Drosophila $\cdot$ PDA

\section{Introduction}

Vision begins with the absorption of a photon of light by the visual pigment, rhodopsin. In most vertebrate photoreceptors, photon absorption causes photoisomerization of the chromophore 11-cis retinal to all-trans retinal, which creates the photoactivated rhodopsin state, metarhodopsin II. This state activates a G-protein coupled phototransduction cascade culminating in a change of the membrane potential, the receptor potential. To avoid saturation and ensure high temporal resolution it is essential that the active metarhodopsin state is rapidly inactivated, which is achieved by phosphorylation and binding to arrestin. Inactivation of the metarhodopsin II state is rapidly further ensured by hydrolysis and dissociation of the all-trans retinal. In invertebrate microvillar photoreceptors, photoinduced isomerization of the chromophore, commonly 11-cis retinal or 11-cis 3-hydroxy retinal, results in a thermostable metarhodopsin state, which, as in vertebrates, activates a G-protein to trigger phototransduction. Active invertebrate metarhodopsins are also inactivated by binding to arrestin, but, at least in flies, without requirement for prior phosphorylation (review Wang and Montell 2007; Hardie and Postma 2008; Katz and Minke 2009; Yau and Hardie 2009).

In a normal diurnal environment, photoreceptors are constantly bombarded by light, resulting in a decrease of the rhodopsin content. Mechanisms must therefore be in place to regenerate rhodopsin and thus maintain light sensitivity. In vertebrate photoreceptors, all-trans retinal is reisomerized to 11-cis retinal via a complex enzymatic 
cascade occurring mainly in the retinal pigment epithelium or Müller cells (rod and cone photoreceptors, respectively, Saari 2000; Mata et al. 2002; Ala-Laurila 2006; review von Lintig et al. 2010). By contrast, the thermostable metarhodopsin of most invertebrate photoreceptors can be reconverted to rhodopsin simply by absorption of another photon, which reisomerizes the chromophore whilst still attached to the opsin (reviews Hamdorf 1979; Stavenga 1995; Hardie and Postma 2008). Nevertheless, even in invertebrate photoreceptors enzymatic turnover and renewal of the chromophore are also essential mechanisms to maintain rhodopsin content, at least in the medium to long term (Schwemer 1989; Goldsmith and Bernard 1985).

The thermostable metarhodopsin state can have profound consequences for the receptor potential. Notably in dipteran flies such as the fruitfly Drosophila and the blowfly Calliphora, excessive conversion of the blueabsorbing rhodopsin into its orange-absorbing metarhodopsin results in a prolonged depolarizing afterpotential (PDA) when the number of metarhodopsin molecules outtitrates the available arrestin necessary for terminating phototransduction (Minke et al. 1975; Hamdorf 1979; Dolph et al. 1993; Belušič et al. 2010; Satoh et al. 2010). Photoreceptors are effectively blinded during a PDA; however, flies are unlikely to experience this problem in their normal habitat, because the broad-band character of natural light does not create a very large metarhodopsin content, and moreover, long-wavelength stray light filtering through the red screening pigments photoreconverts existing metarhodopsin into the rhodopsin state. It has long been recognized that this strategy ensures that a high rhodopsin content is maintained even under bright illumination (Stavenga et al. 1973; Stavenga 2002). However, exactly how this elegant strategy functions under natural conditions has not been quantitatively evaluated.

In virtually all other insect species that have been studied a very different situation exists, however. The dominant visual pigment class of most insects is a greenabsorbing rhodopsin, which is photoconverted into a blueabsorbing metarhodopsin (Hamdorf 1979; Stavenga and Schwemer 1984). In this case a photochemical reconversion system like that of flies would not work, and in fact could be potentially disastrous, because screening pigment allowing red stray light to enter the photoreceptors would favour photoconversion of the green rhodopsins instead of their metarhodopsin. This would generate spurious responses to off-axis light and result in a reduction of light sensitivity. Presumably, therefore, green-sensitive photoreceptors must heavily rely on visual pigment turnover and renewal (Goldsmith and Bernard 1985).

In the present paper, we review the photochemistry of invertebrate visual pigments. We quantitatively evaluate how the metarhodopsin level is controlled by screening pigments, arrestin concentration, and visual pigment turnover under natural conditions. We firstly analyse the uniquely built fly eyes, because of the extensive knowledge of these eyes and their prominent role in invertebrate vision research. We then extend our analysis to show how the rapid pigment turnover reported from green-sensitive photoreceptors (e.g. Bernard 1983a, b) plays a crucial role in controlling visual pigment concentration and sensitivity under the full range of environmental intensities.

\section{Materials, methods and theory}

Natural light spectra

Photon flux spectra radiated by the sky, sun, and grass were measured on 5 June 1997 under cloudless, bright light conditions with an InstaspecIII (Oriel Instruments) spectrometer. Figure 1a presents normalized spectra, which are used in the initial analyses that treat the photoequilibria of the visual pigments. The measured spectra were in good agreement with those of McFarland and Munz (1976); see also Menzel (1979, Fig. 1). In the latter experiments, the spectral radiance was measured at midday of a clear sky (in Ithaca, New York) within a cone of $15^{\circ}$, which corresponds to 0.054 std or 177 sqdeg (std is steradian and sqdeg is square degree). The measured radiances had peak values, for sky light at $\lambda_{\max } \approx 455 \mathrm{~nm}, 5 \times 10^{12}$ photons $\mathrm{cm}^{-2} \mathrm{~s}^{-1} \mathrm{~nm}^{-1}$ or $E_{\mathrm{s}, \max }=300$ photons $\mu \mathrm{m}^{-2} \mathrm{~s}^{-1} \mathrm{~nm}^{-1} \mathrm{sqdeg}^{-1}$; for light from grass (a meadow), at $\lambda_{\text {max }} \approx 555 \mathrm{~nm}, E_{\mathrm{g}, \text { max }}=70$ photons $\mu \mathrm{m}^{-2} \mathrm{~s}^{-1} \mathrm{~nm}^{-1} \mathrm{sqdeg}^{-1}$; for sunlight, radiating light from a small angle, being $32^{\prime}=0.53^{\circ}$, at $\lambda_{\max } \approx$ $605 \mathrm{~nm}$, the resulting irradiance is $W_{\max }=8 \times 10^{6}$ photons $\mu \mathrm{m}^{-2} \mathrm{~s}^{-1} \mathrm{~nm}^{-1}$.

\section{Screening pigments}

Fly eyes contain two main types of screening pigments; firstly the red or red-brown pigments of the screening pigment cells, and secondly the yellow pigments of the mobile granules inside the photoreceptor cells that together function as a light-controlling pupil mechanism. In the dark-adapted state, the pupillary pigment granules are concentrated in the photoreceptor cell soma, at a distance from the rhabdomere, but upon light adaptation the granules are pulled towards the rhabdomere, where they absorb light propagating along the rhabdomere in so-called waveguide modes (Franceschini and Kirschfeld 1976; Stavenga 2004). The blowfly Calliphora vicina has red screening pigment and yellow pupillary pigment (Fig. 1b). The pigments of most other insect eyes absorb over a broad wavelength range and approximate neutral density filters for the visual pigments (Fig. 1c). 

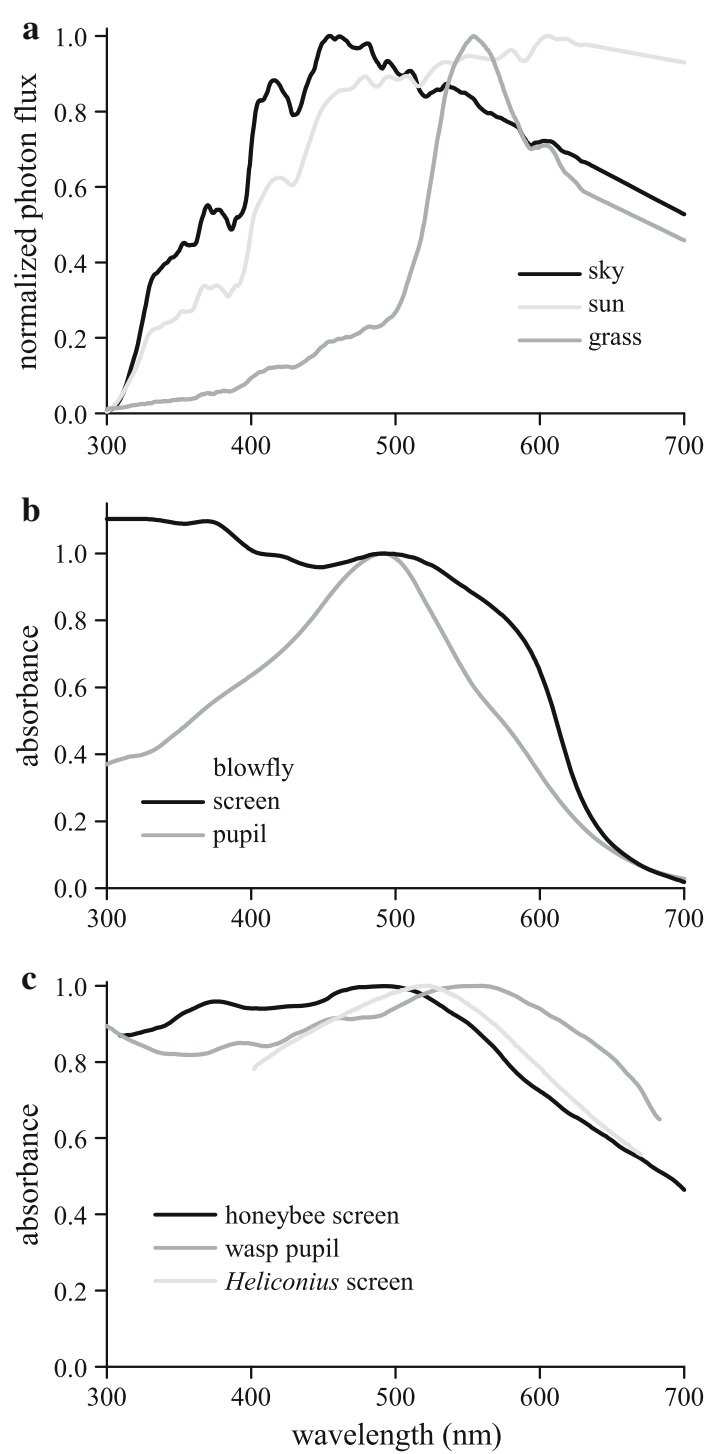

Fig. 1 a Spectral distribution of the photon flux from natural sources: the sky, the sun and grass. b Absorbance spectra of the pigments in the eye of the blowfly $C$. vicina. The red screening pigment is located distally in the eye in the screening pigment cells (from Schwemer 1979), and the yellow pupillary pigment is located in the soma of the photoreceptor cells (from Stavenga 2004, Fig. 7). c Absorbance spectra of eye pigments of a few other insects: the screening pigment spectrum of the honey bee Apis mellifera (from Strother and Casella 1972, Fig. 8), the pupillary pigment of the wasp Vespa germanica (from Stavenga and Kuiper 1977, Fig. 10), and the screening pigment of a Heliconius butterfly (from Langer and Struwe 1972, Fig. 6)

Photochemistry of invertebrate visual pigments

The photochemistry of invertebrate visual pigments is described by the scheme $R \Leftrightarrow M$. The rate constants $k_{\mathrm{R}}$ and $k_{\mathrm{M}}$ for the photoconversions of $R$ to $M$ and of $M$ to $R$, respectively, for

$k_{i}=\int \beta_{i}(\lambda) I(\lambda) \mathrm{d} \lambda$ with $i=R, M ; \lambda$ is the wavelength; $\beta_{\mathrm{R}}(\lambda)=\gamma_{\mathrm{R}} \alpha_{\mathrm{R}}(\lambda)$ and $\beta_{M}(\lambda)=\gamma_{M} \alpha_{M}(\lambda)$ are the photosensitivities, with $\alpha_{R}(\lambda)$ and $\alpha_{M}(\lambda)$ the molecular absorbance coefficients of rhodopsin and metarhodopsin, and $\gamma_{R}$ and $\gamma_{M}$ the quantum efficiencies for photoconversion; $I(\lambda)$ is the photon flux. Continuous illumination of the visual pigment establishes a photoequilibrium with a metarhodopsin fraction

$f_{\mathrm{Me}}=1 /\left(1+k_{\mathrm{M}} / k_{\mathrm{R}}\right)$.

The conversion follows an exponential time course with time constant $\tau_{\mathrm{c}}=1 /\left(k_{\mathrm{R}}+k_{\mathrm{M}}\right)$. In the case of monochromatic illumination $f_{\mathrm{Me}}(\lambda)=1 /\left[1+\varphi \alpha_{\mathrm{M}}(\lambda) / \alpha_{\mathrm{R}}(\lambda)\right]$, with $\varphi=\gamma_{\mathrm{M}} / \gamma_{\mathrm{R}}$ the relative quantum efficiency (see e.g. Stavenga and Schwemer 1984; Stavenga et al. 2000). For the main visual pigment of the blowfly $C$. vicina a value of $\varphi=0.94$ was reported (Schwemer 1979), but for most other visual pigments $\varphi$ appears to be lower, around 0.7 (see Stavenga and Schwemer 1984). Figure 2 gives as examples the blue-green absorbing rhodopsin R490 (peak wavelength $490 \mathrm{~nm}$ ) of the R1-6 photoreceptors of the blowfly $C$. vicina with its strongly bathochromic shifted, orange absorbing metarhodopsin M575 (Fig. 2a; from Stavenga 2010) and the green-absorbing rhodopsin R532 from the eye of the comma butterfly Polygonia c-album with its hypsochromic shifted, bluegreen absorbing metarhodopsin M492 (Fig. 2b; from Vanhoutte and Stavenga 2005). The latter visual pigment can be taken as characteristic for the dominant, greenabsorbing visual pigment class populating the majority of the photoreceptors in most insects (Hamdorf 1979; Briscoe and Chittka 2001; Briscoe et al. 2003; Wakakuwa et al. 2007). For simplicity and convenience, we assume hereafter that this pigment is also representative for the green visual pigment of honeybees, although strictly speaking this will be slightly incorrect, because the spectral sensitivity of the honeybee green receptor peaks at $544 \mathrm{~nm}$ (Peitsch et al. 1992). The absorbance of the metarhodopsin in the ultraviolet is assumed to be lower than that of the rhodopsin (Fig. 2b), but the precise spectral characteristics of insect visual pigments in the UV are uncertain (see Stavenga 2010). The dependence of the metarhodopsin fraction in photoequilibrium on monochromatic illumination is completely opposite for the two visual pigments of Fig. 2a and $b$. Whereas, red light causes a photoequilibrium with negligible metarhodopsin for the blowfly visual pigment (Fig. 2c), negligible rhodopsin results in the case of the green-absorbing rhodopsin (Fig. 2d; see also Hamdorf 1979).

Photoconversion speed of visual pigments in a fly rhabdomere and a honeybee or butterfly rhabdom

In insect eyes, visual pigment is contained in the rhabdomeres. The rhabdomeres of R1-6 photoreceptors of the 

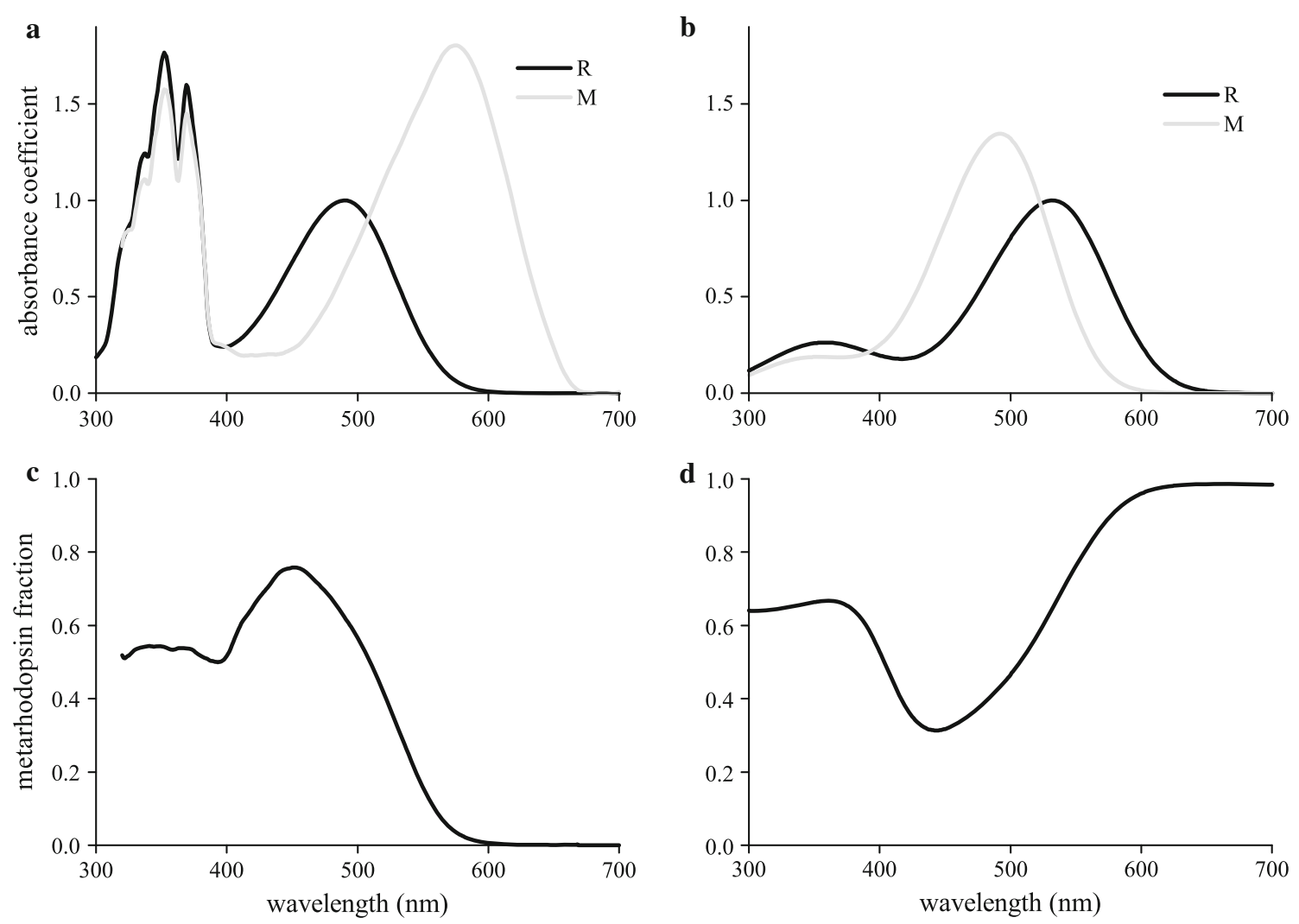

Fig. 2 Spectral properties of insect visual pigments. a Absorbance spectra of the two thermostable states, rhodopsin (R490) and metarhodopsin (M575), of the main visual pigment of the blowfly C. vicina; the fine-structured absorbance in the ultraviolet is due to 3-hydroxy-retinol, which sensitizes the visual pigment molecule, both in the rhodopsin and in the metarhodopsin state. b Absorbance spectra

of the rhodopsin (R532) and metarhodopsin (M492) of a typical green-sensitive visual pigment. c, d The metarhodopsin fraction in photoequilibrium as a function of monochromatic illumination, calculated with the spectra of $\mathbf{a}$ and $\mathbf{b}$, using a relative quantum efficiency $\varphi=0.94$ (blowfly) and $\varphi=0.71$ (green visual pigment)

fruitfly, Drosophila, are 80-100 $\mu \mathrm{m}$ long cylinders, tapering from 2 to $1 \mu \mathrm{m}$. Each rhabdomere consists of 30-50,000 tightly packed microvilli, each containing about 1,000 visual pigment molecules (Hardie and Postma 2008). Hence, the concentration of the $4 \times 10^{7}$ visual pigment molecules in a rhabdomere volume of $(\pi / 4)\left(1.5^{2}\right) 90=$ $159 \mu^{3}$ is $C=2.5 \times 10^{5} \mu \mathrm{m}^{-3}$. With a specific absorbance coefficient at the peak wavelength $\kappa_{\max }=$ $5.0 \times 10^{-3} \mu \mathrm{m}^{-1}$ of the rhabdomere medium (Warrant and Nilsson 1998), the molecular absorbance coefficient becomes $\alpha_{\max }=\kappa_{\max } / C=2.0 \times 10^{-8} \mu \mathrm{m}^{2}$ (for bovine rhodopsin $\alpha_{\max }=1.56 \times 10^{-8} \mu \mathrm{m}^{2}$; Dartnall 1972). If the quantum efficiency for photoconversion of bovine rhodopsin, $\gamma_{R}=0.67$ (Dartnall 1972), is the same for fly rhodopsin, then the peak photosensitivity becomes $\beta_{\mathrm{R}, \max }=1.3 \times 10^{-8} \mu \mathrm{m}^{2}$. (For similar calculations made for butterfly visual pigment, see Vanhoutte and Stavenga 2005.) In addition to the photosensitivity, calculation of the photoconversion rate constant (Eq. 1) requires the photon flux in the rhabdomere, $I(\lambda)$. The visual pigment receives light via a facet lens, which focuses incident light into the

rhabdomere. In a geometrical approach (see e.g. Stavenga 2003), when a facet lens with diameter $D_{1}$ and focal length $f$ concentrates light from a wide-field source (e.g. sky) with radiance $E_{\mathrm{s}}(\lambda)$ photons $\mu \mathrm{m}^{-2} \mathrm{~s}^{-1} \mathrm{~nm}^{-1} \mathrm{sqdeg}^{-1}$ into a rhabdomere with diameter $D_{\mathrm{r}}$, the photon flux $I(\lambda)=$ $(\pi / 4)\left(D_{1} / f\right)^{2} E_{\mathrm{s}}(\lambda)$, with dimension photons $\mu \mathrm{m}^{-2} \mathrm{~s}^{-1} \mathrm{~nm}^{-1}$, and with the angle $D_{1} / f$ in degrees. For the case of the blowfly, assuming a facet lens diameter $D_{1}=25 \mu \mathrm{m}$, focal length $f=50 \mu \mathrm{m}$, and rhabdomere diameter $1.5 \mu \mathrm{m}$, the lens concentration factor $(\pi / 4)\left(D_{1} / f\right)^{2}$ becomes 645 sqdeg. Using this value together with the peak photosensitivities and the visual pigment spectra of Fig. 2a, the photoconversion rate constants for sky light (Fig. 1a) are $k_{\mathrm{R}}=0.34 \mathrm{~s}^{-1}$ and $k_{\mathrm{M}}=0.52 \mathrm{~s}^{-1}$, so that the time constant for photoconversion is $\tau_{\mathrm{c}}=1 /\left(k_{\mathrm{R}}+k_{\mathrm{M}}\right)=1.2 \mathrm{~s}$; for light from grass $k_{\mathrm{R}}=0.02 \mathrm{~s}^{-1}, k_{\mathrm{M}}=0.09 \mathrm{~s}^{-1}$, and $\tau_{\mathrm{c}}=1 /\left(k_{\mathrm{R}}+k_{\mathrm{M}}\right)=9.1 \mathrm{~s}$. The photon flux from the sun, entering on-axis an ommatidium with acceptance angle sufficiently larger than the spatial angle of the sun is $I(\lambda)=\left(D_{1} / D_{\mathrm{r}}\right)^{2} W(\lambda)$, with $\left(D_{\mathrm{l}} / D_{\mathrm{r}}\right)^{2}=278$ and $W(\lambda)$ the irradiance of the sun (dimension photons $\mu \mathrm{m}^{-2} \mathrm{~s}^{-1} \mathrm{~nm}^{-1}$ ). 
The photoconversion rate constants for sun light then become $k_{\mathrm{R}}=6.3 \times 10^{3} \mathrm{~s}^{-1}$ and $k_{\mathrm{M}}=3.3 \times 10^{3} \mathrm{~s}^{-1}$, so that $\tau_{\mathrm{c}}=1 /\left(k_{\mathrm{R}}+k_{\mathrm{M}}\right)=0.1 \mathrm{~ms}$. Assuming that the photosensitivity and optical parameters for the blowfly rhodopsin of Fig. 2a and the green-absorbing visual pigment of Fig. $2 b$ are the same, the corresponding values for the latter visual pigment are: for sky light $k_{\mathrm{R}}=0.29 \mathrm{~s}^{-1}$, $k_{\mathrm{M}}=0.24 \mathrm{~s}^{-1}$, and $\tau_{\mathrm{c}}=1 /\left(k_{\mathrm{R}}+k_{\mathrm{M}}\right)=1.9 \mathrm{~s}$; for light from grass $k_{\mathrm{R}}=0.04 \mathrm{~s}^{-1}, \quad k_{\mathrm{M}}=0.02 \mathrm{~s}^{-1}$, and $\tau_{\mathrm{c}}=$ $1 /\left(k_{\mathrm{R}}+k_{\mathrm{M}}\right)=16.1 \mathrm{~s}$; and for sunlight $k_{\mathrm{R}}=3.3 \times 10^{3} \mathrm{~s}^{-1}$, $k_{\mathrm{M}}=2.6 \times 10^{3} \mathrm{~s}^{-1}$, and $\tau_{\mathrm{c}}=1 /\left(k_{\mathrm{R}}+k_{\mathrm{M}}\right)=0.17 \mathrm{~ms}$.

\section{Results}

The metarhodopsin fraction resulting from natural illuminants filtered by ocular pigments

When the insect visual pigments of Fig. 2 are irradiated for a sufficiently prolonged period, a photoequilibrium will be established depending on the spectral properties and quantum efficiencies of the two photointerconvertible states, rhodopsin and metarhodopsin, and the spectral composition of the light source. For the blowfly R1-6 visual pigment of Fig. 2a, the metarhodopsin fractions resulting with unfiltered light from the sky, sun and grass (Fig. 1a), calculated with Eq. 2 and the rate constants of photoconversion following from Eq. 1, are about 0.4, 0.35, and 0.2 , respectively (Fig. 3a, pigment density 0 ). For the green rhodopsin of Fig. 2b, which is taken as an exemplar for the long-wavelength absorbing visual pigments of invertebrates, the metarhodopsin in photoequilibrium with unfiltered light is about 0.6.
Filtering the natural illuminants with the photostable pigments of the screening pigment cells or the pupillary pigment of the photoreceptor cells modifies the light composition and thus the metarhodopsin fraction in photoequilibrium. Both the screening and the pupillary pigment filters can be assumed to be located distally from the visual pigment (Roebroek and Stavenga 1990a). In the case of the blowfly, when the three natural lights are filtered by the red pigment of the screening pigment cells, the metarhodopsin content progressively diminishes with increasing pigment density (Fig. 3a; blowfly, screen). This is precisely the rationale of the long-wavelength transmittance of the screening pigments of fly eyes (Stavenga et al. 1973; Stavenga 2002). Similarly, the metarhodopsin fraction in photoequilibrium diminishes with the increasing density of the yellow-pigmented pupil as it closes in as a function of the light intensity entering the ommatidia onaxis (Fig. 3a; blowfly, pupil). Opposite effects occur in a honeybee or butterfly eye with a green-absorbing rhodopsin of Fig. $2 b$ and the screening pigment of Fig. 1c when illuminated by the three natural spectral lights of Fig. 1a. With increasing density of the screening pigment, the metarhodopsin fraction in photoequilibrium slightly (but still steadily) increases from about 0.6 to about 0.7 , because of the relative increase of long-wavelength light (Fig. 3a; honeybee, screen).

The calculations for Fig. 3a have been done assuming that all visual pigment molecules receive the same spectral light flux. However, invertebrate photoreceptors have their visual pigments concentrated in rhabdomeres. The separate rhabdomeres in an ommatidium of a fly compound eye act as separate optical waveguides, but in most insects, including honeybees and butterflies, the rhabdomeres are
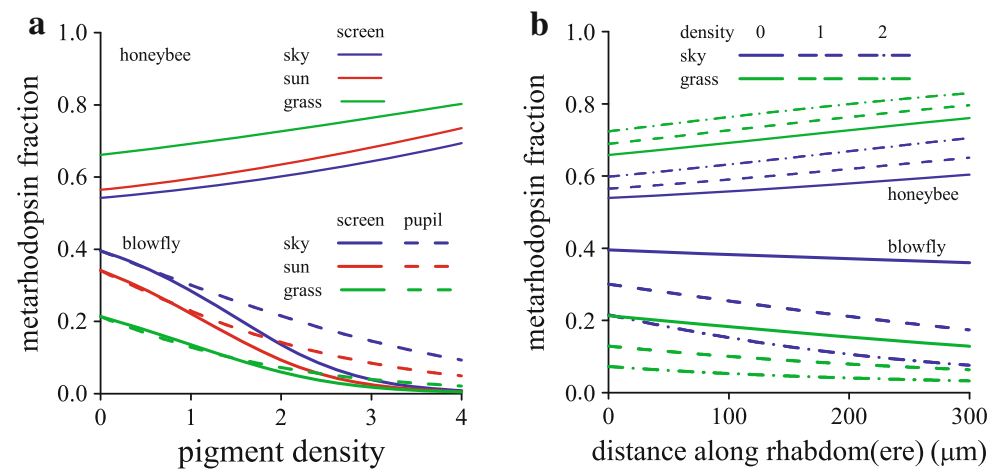

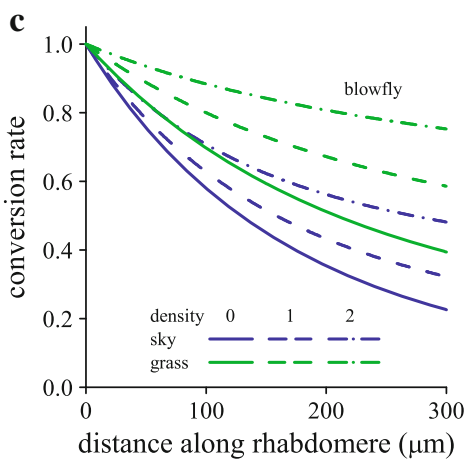

Fig. 3 Photoequilibria resulting after prolonged illumination of the visual pigments of Fig. 2 with the three natural light sources of Fig. 1a, filtered by the various photostable pigments: for the blowfly, the red screening pigment and the yellow pupillary pigment of Fig. $1 \mathrm{~b}$, and for the honeybee the screening pigment of Fig. 1c. a The resulting metarhodopsin fractions for the blowfly are given by the lower six curves and by the upper three curves for the honeybee. The pigment density indicates the value at the wavelength of maximal absorbance (a density of 1, 2, 3... means attenuation by a factor of 10 ,
$100,1,000 \ldots)$. b Photoequilibria resulting after prolonged illumination with sky and grass light of the blowfly and honeybee visual pigments in a $300 \mu \mathrm{m}$ long rhabdom(ere), when filtered distally by the blowfly pupillary pigment and honeybee screening pigment, respectively, with peak densities 0 (no filter), 1 and 2. c Dependence of the photoconversion rate on the distance from the rhabdomere tip, normalized to the value at the tip, for the blowfly visual pigment illuminated with sky and grass light, for the same three densities of filtering pigment as in $\mathbf{b}$ 
joined in a fused rhabdom, which acts as an individual optical waveguide. The visual pigments absorb part of the light flux that propagates in the rhabdom(ere), and this selfscreening effect modifies the spectral composition along the waveguide's longitudinal axis. For the blowfly, Fig. 3b shows the dependence of the metarhodopsin fraction in photoequilibrium as a function of the distance from the rhabdomere tip, when light from the sky or grass is not filtered (density 0), or distally filtered by the yellow pupillary pigment with a peak optical density of 1 or 2, i.e. the incident light is then reduced at the pupil peak wavelength by a factor 10 or 100 , respectively. The slight decrease in metarhodopsin fraction with increasing distance is due to the relative increase in red light along the length of the rhabdomere. With sunlight the resulting metarhodopsin fractions take intermediate values between those for light from the sky and grass (not shown). In the case of the honeybee, simply assuming that all rhabdomeres in the fused rhabdom contain green visual pigment, the dependence of the metarhodopsin fraction on the location in the rhabdom behaves opposite to that of the blowfly. The relative increase of red light with increasing distance from the rhabdom tip causes a further slight increase of the metarhodopsin fraction (Fig. 3b).

Due to the self-screening of the visual pigment, the effective light flux decreases along the visual waveguides, and thus the photoconversion rate constants decrease. Figure $3 \mathrm{c}$ shows the value of the photoconversion rate constant normalized to the value at the rhabdom(ere) tip as a function of the distance from the tip for the same cases as treated in Fig. 3b. The effective reduction in light flux appears to be at most about a factor 3 (half a log unit) for broad-band natural light. Figure $3 \mathrm{c}$ presents only the case of the blowfly; a similar decrease of the conversion rate occurs in the fused rhabdom of bees and butterflies.

Dependence of blowfly metarhodopsin on the pupil mechanism

An experimental demonstration of how the metarhodopsin fraction depends on the density of the pupillary pigment when a blowfly eye is irradiated with white light is presented in Fig. 4 (modified from Stavenga 1980). An eye of a blowfly was dark adapted for $1 \mathrm{~min}$, and then illuminated for $15 \mathrm{~s}$ with bright white light from a xenon lamp, the spectrum of which approximates sunlight. The pupil closed within a few seconds (Fig. 4a). This experiment was repeated with illuminations of different durations and subsequently the metarhodopsin fraction was determined by measuring, in the dark-adapted, open-pupil state, the rhabdomere transmittance at the peak of the metarhodopsin spectrum, from which the absorbance due to the metarhodopsin was calculated. The outcome was that the pupil
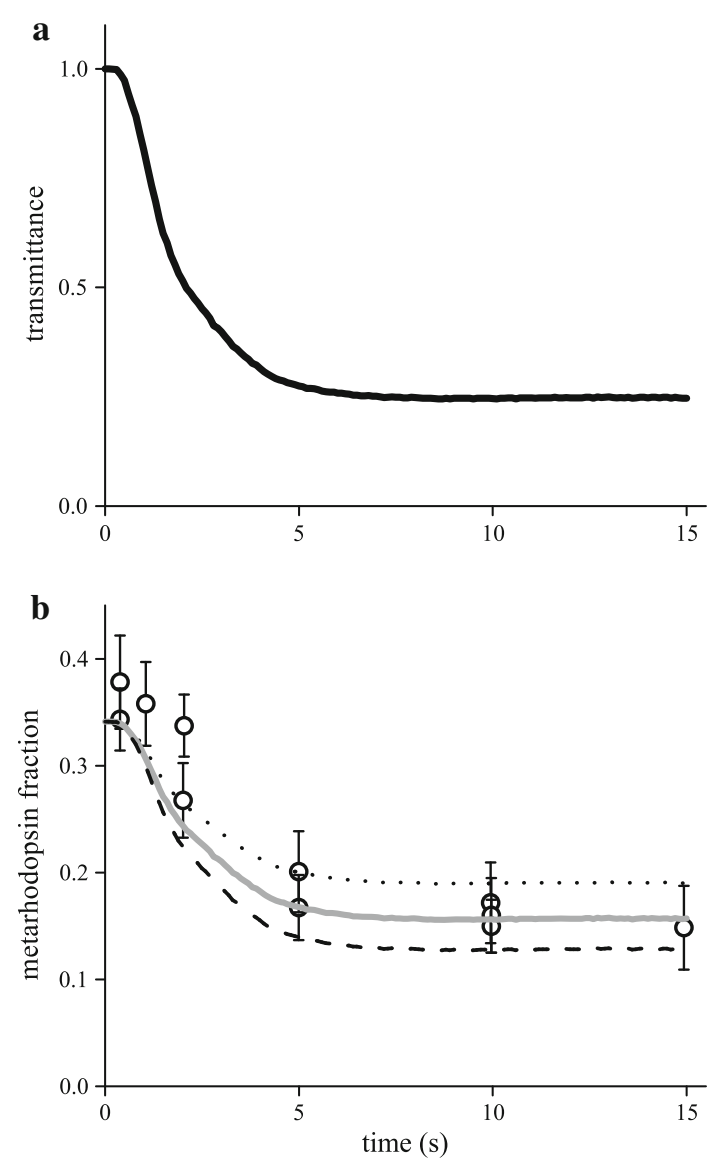

Fig. 4 Closure of the pupil in blowfly eyes by bright white light, which causes a low metarhodopsin fraction. a Time course of the transmittance of the pupil in the blowfly eye measured with a bright, broad-band (white) xenon light source after pre-adaptation with red light and an additional $1 \mathrm{~min}$ dark adaptation time. The measured signal (data from Stavenga 1980, Fig. 5) was integrated over the complete spectrum. b The metarhodopsin fraction resulting after various periods of illumination (symbols with error bars, from Stavenga 1980, Fig. 5) and the time course of the metarhodopsin fraction in photoequilibrium calculated for sun light (Fig. 1a) filtered by the blowfly pupillary pigment (Fig. 1b), the optical density of which increases during the illumination time as derived from $a$, reaching a peak value of 1.4 (dotted), 1.8 (grey), and 2.2 (dashed) at maximum pupil closure (see also Fig. 3a)

reduced the initial metarhodopsin fraction from about 0.35 to about 0.15 (Fig. $4 \mathrm{~b}$, symbols). The time course of the metarhodopsin fraction during the white illumination period closely resembles the time course of the pupil transmittance (Fig. 4a), indicating that the illumination was so bright that photoequilibria were established effectively instantaneously $(<1 \mathrm{~s})$.

The effective pupil density responsible for the decreasing metarhodopsin can be estimated by calculating the time course of the metarhodopsin fraction with the same procedure as applied for Fig. 3, assuming that the spectral distribution of the effective illumination approximated that of the sun filtered by the pupillary pigment and neglecting 
the slightly inhomogeneous composition of the visual pigment in the rhabdomeres (Fig. 3b). The calculated time course of the metarhodopsin fraction (Fig. 4b, continuous curve) settles at a value $0.16 \pm 0.03$, which corresponds to a pupil peak density of about $1.8 \pm 0.4$.

Figures 3 and 4 illustrate that the red screening pigment of blowfly eyes, together with the yellow pupillary pigment, effectively reduce the metarhodopsin fraction in bright light conditions. However, in the case of the green rhodopsin of bees and butterflies bright natural lights will always create a large metarhodopsin fraction, which could well be deleterious for vision. Fortunately only a small proportion of the metarhodopsin molecules is then actively contributing to the photoreceptor signal, because most of them will be either inactivated by arrestin molecules or degraded, as is discussed below.

The visual pigment-arrestin cycle

The rhodopsin and metarhodopsin state of the visual pigment molecules can be distinguished by whether or not they are bound to an arrestin molecule. (Fly photoreceptors express two distinct arrestin types: here arrestin refers to arrestin 2, the dominant isoform that blocks the active metarhodopsin state; Hardie and Postma 2008.) The visual pigment state without an arrestin is called here the active state and with a bound arrestin it is inactive. In the simplified visual pigment-arrestin cycle of Fig. 5 photoconversion of the native, active rhodopsin, $\mathrm{R}_{\mathrm{a}}$, creates the active metarhodopsin state, $M_{a}$, i.e. the visual pigment state that triggers the phototransduction process. Upon binding arrestin, $M_{a}$ converts into inactive metarhodopsin, $M_{i}$.

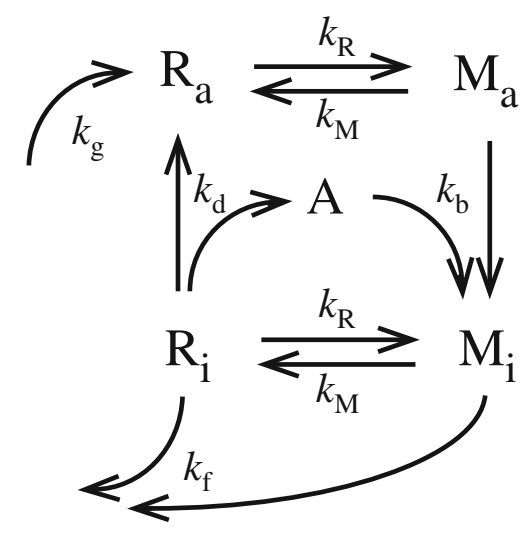

Fig. 5 Visual pigment-arrestin cycle. Photoconversion of active rhodopsin, $R_{\mathrm{a}}$, creates active metarhodopsin, $M_{\mathrm{a}}$, which upon binding arrestin, A, becomes inactive metarhodopsin, $M_{\mathrm{i}}$. Photoconversion of $M_{\mathrm{i}}$ creates inactive rhodopsin, $R_{\mathrm{i}}$, which upon arrestin release converts into the native rhodopsin, $R_{\mathrm{a}}$. The light-induced conversion processes have rate constants $k_{\mathrm{R}}$ and $k_{\mathrm{M}}$, the rate constants of arrestin binding and dissociation are $k_{\mathrm{b}}$ and $k_{\mathrm{d}} . R_{\mathrm{i}}$ and $M_{\mathrm{i}}$ are degraded with rate constant $k_{\mathrm{f}}$, and $R_{\mathrm{a}}$ is regenerated with rate constant $k_{\mathrm{g}}$
Photoconversion of $M_{i}$ creates inactive rhodopsin, $R_{i}$, which upon arrestin release returns to the active rhodopsin state $\mathrm{R}_{\mathrm{a}}$. Metarhodopsin is also phosphorylated (and rhodopsin dephosphorylated) during the pigment cycle; however, we have excluded this from the analysis, since most available data from flies indicate that the phosphorylation state of metarhodopsin does not influence its activity or its ability to bind to arrestin (Plangger et al. 1994; Vinós et al. 1997; Liu et al. 2008).

The distribution of the visual pigment molecules over the possible states can be quantitatively assessed with the formalism presented in "Appendix", when the visual pigment and arrestin concentration as well as the conversion rate constants are known. In the fruitfly Drosophila, there are about $R_{0}=1,000$ visual pigment molecules per photoreceptor microvillus. The number of arrestin molecules per microvillus $\left(A_{0}\right)$ varies because arrestin undergoes rapid and reversible translocation between the cell body and the rhabdomere depending on the metarhodopsin fraction, $f_{\mathrm{M}}$ (Satoh et al. 2010). When most of the visual pigment is in the rhodopsin state $\left(f_{\mathrm{M}}<0.1\right)$, only $\sim 25 \%$ of arrestin is localized to the rhabdomere, equivalent to $A_{0}=90$ molecules per microvillus. As $f_{\mathrm{M}}$ increases, arrestin moves into the rhabdomere in direct proportion to $f_{\mathrm{M}}$ until it reaches a value of $\sim 0.37$, at which point all available arrestin, equivalent to $A_{0}=370$, is now in the rhabdomere (Satoh et al. 2010). The effective time constant of metarhodopsin inactivation for weak light pulses is $1 / k_{\mathrm{b}} A_{0}=23 \mathrm{~ms}$ (Liu et al. 2008); hence, with $A_{0}=90$, $k_{\mathrm{b}}=0.48 \mathrm{~s}^{-1}$ molecule $^{-1}$. The rate constant for arrestin release following photoreconversion of $\mathrm{M}_{\mathrm{i}}$ to $\mathrm{R}_{\mathrm{i}}, k_{\mathrm{d}}$, is rapid (Satoh et al. 2010) and taken to be $1 \mathrm{~s}^{-1}$. The diagram of Fig. 5 also incorporates visual pigment turnover. The arrestin-bound states, $\mathbf{M}_{\mathrm{i}}$ and $\mathrm{R}_{\mathrm{i}}$ are vulnerable to degradation with a time constant $k_{\mathrm{f}}$, and rhodopsin regeneration occurs with rate constant $k_{\mathrm{g}}$. The duration of the turnover processes is in the order of hours for fly visual pigment and assumed to be in the order of minutes for the honeybee, as has been shown in butterflies (see "Discussion").

Figure 6 presents two model fly microvilli with $A_{0}=370$ (representative for the fruitfly; Fig. 6a, c, e) and $A_{0}=1,000$ (Fig. 6b, d, f; assumed for the blowfly because of the inability to create a full PDA in this case-see "Discussion"), where the illumination creates a steady state with a total metarhodopsin fraction $f_{\mathrm{Me}}=0.2$. Because of its slow time course, turnover of fly visual pigment was neglected in the calculations. The relative photon flux or $\log$ intensity, $\log I$, was normalized so that at $\log I=0$ the sum of the photoconversion rate constants $k_{\mathrm{R}}+k_{\mathrm{M}}=1 \mathrm{~s}^{-1}$, that is, the time constant for creating a photoequilibrium is $1 \mathrm{~s}$. For the fly visual pigment (Fig. 2a), the time constants for unfiltered light from the 


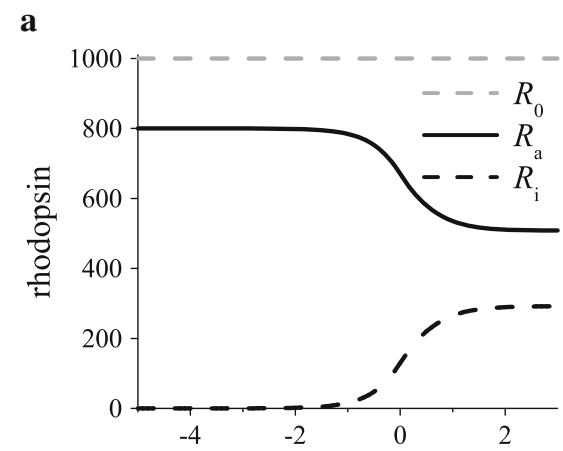

b

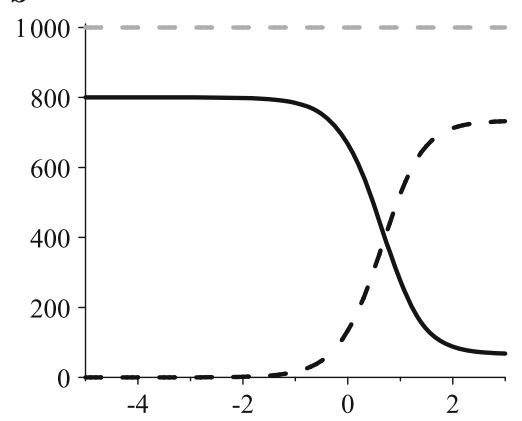

c

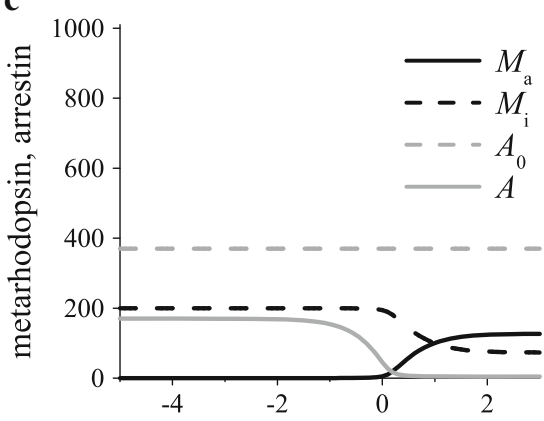

e

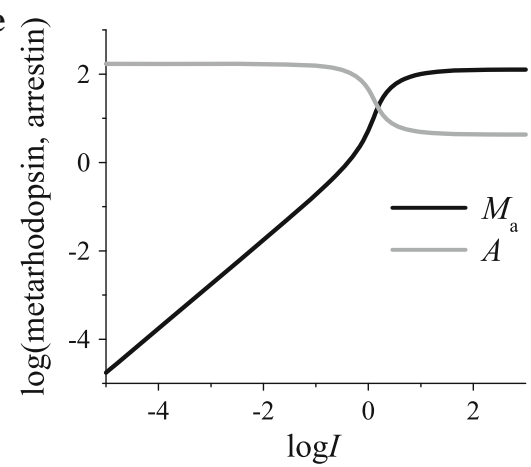

Fig. 6 Population in equilibrium of the different visual pigment states participating in the arrestin cycle in fly microvilli as a function of the light intensity, neglecting visual pigment turnover. The microvilli are assumed to have $R_{0}=1,000$ visual pigment molecules, of which in total 200 exist in one of the two possible metarhodopsin states, $M_{\mathrm{a}}$ and $M_{\mathrm{i}}\left(f_{\mathrm{Me}}=0.2\right)$, and the other 800 are in the $R_{\mathrm{a}}$ and $R_{\mathrm{i}}$ states. Left a, c, e the case of a fruitfly, Drosophila, microvillus with $A_{0}=370$ arrestin molecules. Right $\mathbf{b}, \mathbf{d}, \mathbf{f}$ the case of a blowfly,

sky or grass are 1.2 and $9.1 \mathrm{~s}$, respectively (see Methods), corresponding to $\log I=-0.08$ and $\log I=-0.96$. The time constants increase in proportion to the degree of filtering by the pupil mechanism. For instance, with a pupil mechanism that effectively suppresses the incident light by one $\log$ unit, the time constants increase tenfold to 12 and $91 \mathrm{~s}$, respectively; the visual pigment distribution due to light from the sky and grass then has to be read at $\log I=$ -1.08 and $\log I=-1.96$, respectively.

At low intensities the photoconversion rate constant of metarhodopsin $k_{\mathrm{M}} \ll k_{\mathrm{b}} A$ and $R_{\mathrm{a}}$ and $A$ are effectively d

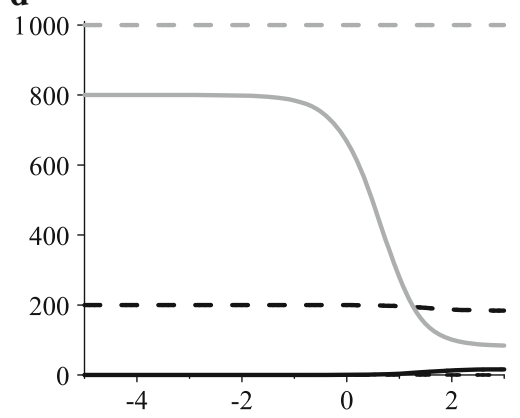

f

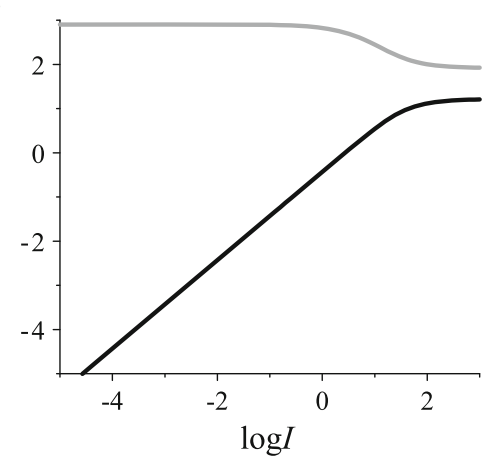

Calliphora, microvillus with $A_{0}=1,000$ arrestin molecules. At $\log I=0$ the photoconversion time constant is $1 \mathrm{~s}$. At low intensities the number of active metarhodopsin molecules, $M_{\mathrm{a}}$, is linearly related to the light intensity. At high intensities that number saturates, depending on the number of available arrestin molecules. The maximum intensity experienced under natural conditions is unlikely to be greater than $\log I=0$ for skylight (see text)

constant, so that the amount of active metarhodopsin, the trigger of the phototransduction process, via the photoconversion rate constant of rhodopsin $k_{\mathrm{R}}$, is linearly related to the light flux: $M_{\mathrm{a}}=R_{\mathrm{a}} k_{\mathrm{R}} /\left(k_{\mathrm{b}} A\right)$; see Fig. $6 \mathrm{e}$, f. The number of active metarhodopsin molecules, $M_{\mathrm{a}}$, rapidly increases around $\log I=0$ (Fig. 6c, e), because there the number of unbound arrestin molecules, $A$, rapidly drops. This does not occur with a much larger amount of arrestin (Fig. 6b, d, f). The visual pigment population states change of course with different choices of the rate constants for arrestin binding and release. For example, because arrestin 

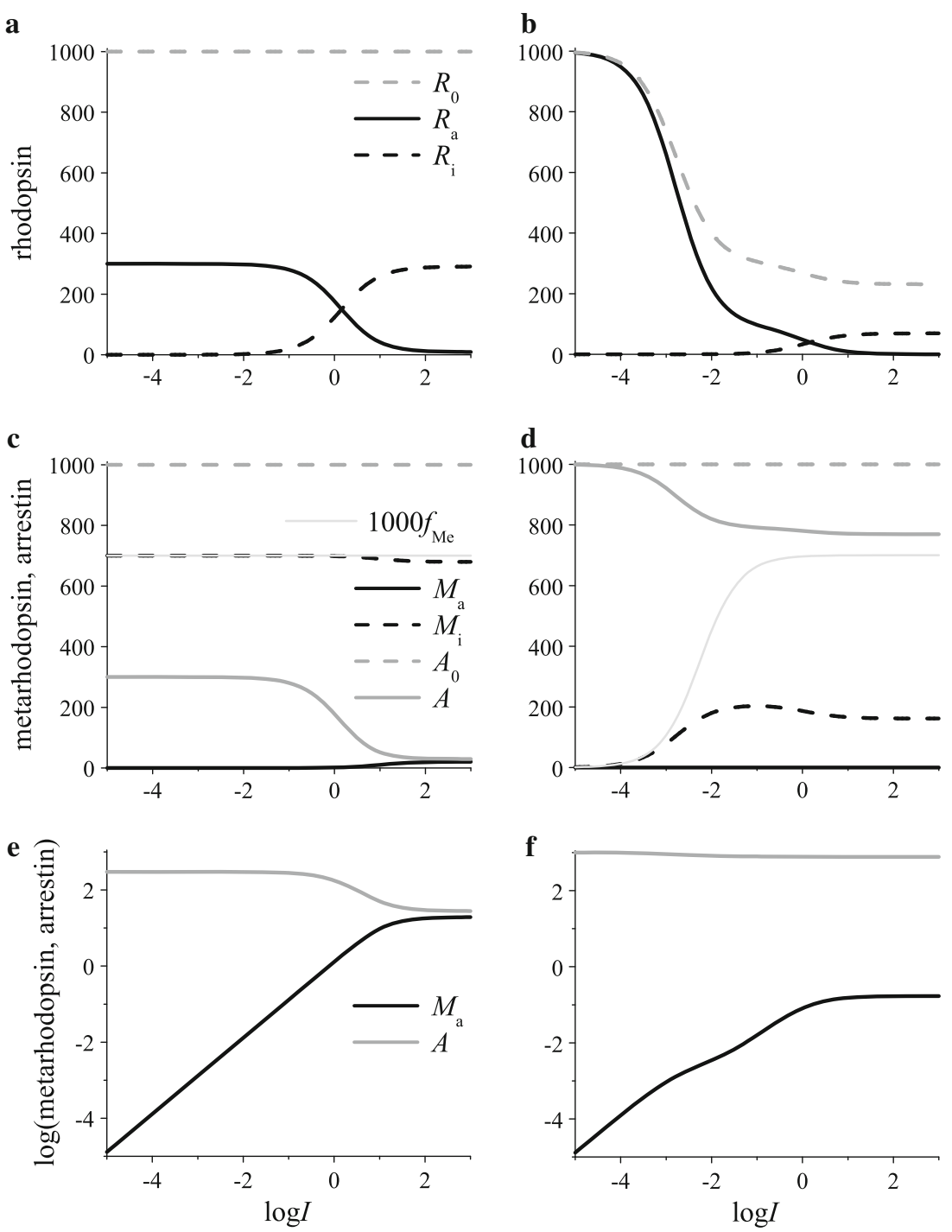

Fig. 7 Population in equilibrium of the different visual pigment states participating in the arrestin cycle in honeybee microvilli with $R_{0}=1,000$ visual pigment molecules and $A_{0}=1,000$ arrestin molecules, as a function of the light intensity. The ratio of the photoconversion rate constants, $k_{\mathrm{M}} / k_{\mathrm{R}}=0.43$, results in a metarhodopsin fraction in equilibrium $f_{\mathrm{Me}}=0.7$ in the absence of pigment turnover. Left a, c, e ignoring pigment turnover; active metarhodopsin increases linearly with intensity, saturating at the very high level of ca 10 molecules per microvillus (c, e). Right $\mathbf{b}, \mathbf{d}, \mathbf{f}$ a microvillus under

binding is $\mathrm{Ca}^{2+}$ dependent (Liu et al. 2008), $k_{\mathrm{b}}$ may increase with light intensity, which would reduce the slope of the $M_{\mathrm{a}}$-curve. Nevertheless, calculations show that the general features presented in Fig. 6 are maintained even when modifying the rate constant values tenfold (not shown).

For the case of the fly we have ignored visual pigment turnover, since overall visual pigment levels remain stable for hours. However, available data from green-sensitive photoreceptors indicate pigment turnover on the time scale

the same conditions, but now including pigment turnover, assuming time constants of 3 min for degradation of $R_{\mathrm{i}}$ and $M_{\mathrm{i}}$ and $10 \mathrm{~min}$ for regeneration of rhodopsin, $R_{\mathrm{a}}$. $f_{\mathrm{Me}}$ now depends strongly on intensity with $f_{\mathrm{Me}}=0$, or, $\sim 100 \%$ visual pigment in the $R_{\mathrm{a}}$ state at very low light intensities, and only approaching the nominal photoequilibrium of $f_{\mathrm{Me}}=0.7$ at high intensities. d With increasing intensity the number of visual pigment molecules is distinctly reduced (bleached) and the total number of number of active molecules, $M_{\mathrm{a}}$, is much less than would be the case without pigment turnover (compare e, f)

of minutes (Bernard 1983a, b). Figure 7 explores the role played by such rapid pigment turnover, as modelled by the visual pigment population states in honeybee and butterfly microvilli. The left hand panels (Fig. 7a, c, e) show the case where pigment turnover is ignored and a steady state is created by natural illumination where the ratio of the rate constants $k_{\mathrm{M}} / k_{\mathrm{R}}=0.43$, which creates $f_{\mathrm{Me}}=0.7$. The total number of visual pigment molecules was again assumed to be $R_{0}=1,000$. The number of arrestin molecules per microvillus was also assumed to be $A_{0}=1,000$, as we 
presume there should be at least sufficient arrestin to inactivate all the metarhodopsin that might be generated under physiological conditions (see "Discussion"). Again, at low intensities the number of active metarhodopsin molecules increases linearly with light intensity. At high intensities the number of non-arrested metarhodopsin molecules saturates, but at a rather high level. In the right hand panels (Fig. 7b, d, f) the same illumination is applied $\left(k_{\mathrm{M}} / k_{\mathrm{R}}=0.43\right)$, but now the effects of visual pigment turnover are included, with time constants of 3 and $10 \mathrm{~min}$ for visual pigment decay and regeneration, respectively. The saturating level of active metarhodopsin is then much lowered due to progressive (meta) rhodopsin degradation and rhodopsin regeneration. Another consequence of visual pigment turnover is that $f_{\mathrm{Me}}$ no longer depends only on the spectral distribution of the illuminant but also its intensity. At low light intensities, where photoconversion of the visual pigment is minimal, $f_{\mathrm{Me}}$ approaches zero (Fig. 7d) and the rhodopsin content-and hence absolute sensitivity_reaches its maximum possible value (Fig. 7b). With increasing intensity, $f_{\mathrm{Me}}$ approaches the nominal photoequilibrium value ( 0.7 in this case; Fig. $7 d)$ and also the total number of visual pigment molecules decreases because rhodopsin regeneration cannot keep up with the metarhodopsin decay ("bleaching"; Bernard 1983a).

\section{Discussion}

The different functions of the screening pigments in blowfly and honeybee eyes

Insect compound eyes are assemblies of ommatidia, structural units with an optical apparatus that feeds incident light into the photoreceptors. The photoreceptor cells are surrounded by pigment cells filled with screening pigments, which form a screen for off-axis light, so as to optimize the spatial resolution of the eye. The absorbance of the pigment cells is generally high at visible wavelengths, but decreases with increasing wavelength, in the red (Fig. 1c). The range of the absorbance spectra is presumably intimately related to the range of the photoreceptor spectral sensitivities. For instance, compared to the honeybee screening pigment, the absorbance spectrum of Heliconius screening pigment extends much further into the red (Fig. 1c), which corresponds to the spectral properties of the green receptor in this butterfly species ( $\lambda_{\max }=570 \mathrm{~nm}$, cf $\lambda_{\max }=544 \mathrm{~nm}$ in the honeybee; Zaccardi et al. 2006; Peitsch et al. 1992).

The absorbance spectrum of the R1-6 rhodopsin in fly eyes is also well covered by the absorbance of the screening pigment (compare Figs. $1 \mathrm{~b}$ and $2 \mathrm{a}$ ). Notably, the absorbance spectrum of the screening pigment rapidly falls off above $600 \mathrm{~nm}$, thus causing the red eye colour (Langer 1975; Stavenga 2002). The resulting benign effect of the red transparency of the screening pigments for maintaining a low metarhodopsin fraction is shown in Fig. 3a, b. The effect of the red screening pigment on a given photoreceptor will depend on where the incident light enters the eye and how much pigment it has to pass before it arrives at the specific photoreceptor. As demonstrated in Fig. 3a, for all treated cases, whether the light source is the sky, the sun or grass, light that passes the screening pigments will be about equally helpful in converting metarhodopsin back into rhodopsin.

The same holds also for the yellow pupillary pigment (Figs. 3, 4). The pigment granules participating in the blowfly pupil mechanism are concentrated in the distal part of the photoreceptor cells and thus enact their light control function in a rather similar fashion as that of the pupil in human eyes (Roebroek and Stavenga 1990a). The granules are increasingly concentrated against the rhabdomere with an increase in incident light flux. At very bright light intensities, the peak absorbance of the pupil of blowfly photoreceptors was estimated by in vivo optical measurements to reach a value $2.8 \pm 0.3 \log$ units (Roebroek and Stavenga 1990b), larger than the estimated $1.8 \pm 0.4$ used in modelling the pupil effect of Fig. $4 \mathrm{~b}$. At any rate, like the red screening pigments, the pupil is an important tool for minimizing the metarhodopsin fraction in blowfly photoreceptors. Both the integrated stray light flooding the eye and the photon flux entering the rhabdomere axially will determine the photoconversion of a photoreceptor's metarhodopsin and the resulting photoequilibrium in a real, living fly eye.

The absorbance spectra of the visual, screening and pupillary pigments of Drosophila differ slightly from the spectra of the blowfly pigments, and also the density of the screening pigments and pupil mechanism in fruitfly eyes are lower (Franceschini 1975; Franceschini and Kirschfeld 1976), but undoubtedly the same principles apply for fly eyes in general. The red screening pigment protects the main, blue-green absorbing rhodopsin of R1-6 photoreceptors, Rh1, but allows red stray light to photoreconvert the bathochromic-shifted, orange-absorbing metarhodopsin. Fly ommatidia have in addition two minor photoreceptors (R7 and R8), expressing one of four further visual pigments: two UV rhodopsins, Rh3 and Rh4 (in R7 cells), a blue absorbing rhodopsin, Rh5 (in R8), all with a bathochromic-shifted metarhodopsin, and a green-absorbing rhodopsin, Rh6 (also in R8), which has a hypsochromicshifted metarhodopsin (Salcedo et al. 1999). These metarhodopsins absorb mainly in the blue to blue-green wavelength range and absorb little in the red, and therefore the photochemistry of Rh3-5 will not be seriously affected by the long-wavelength transmittance of the screening 
pigments. However, the situation is different for Rh6, with rhodopsin and metarhodopsin peak wavelengths $515 \mathrm{~nm}$ and $468 \mathrm{~nm}$, respectively (comparable to the green visual pigment of Fig. 2b), and therefore its photochemical conversions will be vulnerable to red leakage light. Interestingly, the Rh6 metarhodopsin was found to be rather thermolabile when ectopically expressed in R1-6 cells (Salcedo et al. 1999).

As is clear from Fig. 3, green-absorbing rhodopsins, with their hypsochromic blue-absorbing metarhodopsins, cannot benefit from long-wavelength transmitting screening or pupillary pigments. In fact, in honeybee and butterfly eyes light that passes the screening pigment will only have the apparently detrimental effect of photoconverting rhodopsin into metarhodopsin (Fig. 3a, b). The photochemistry of green rhodopsins thus creates quite a challenge, because in photoequilibrium, which is rather rapidly reached at the high intensities of natural light sources (see Methods), the metarhodopsin fraction is predicted to be over 50\% (Fig. 3a, b). This will require special precautions if light sensitivity is to be optimized. The first measure of course, is to make the density of the screening pigment so high that stray, off-axis light remains negligible. This is virtually always realized, because insects generally have very black eyes due to dense screening pigments. Furthermore, insects active in bright environments have pupil mechanisms that reduce the incident light flux and thus lower the photoconversion rate constants to levels suitable for dynamic phototransduction. Nevertheless, after even relatively short exposure to natural illuminants, a substantial fraction of the green rhodopsins will be converted into their metarhodopsin state. This may be acceptable under bright light circumstances when sensitivity is not at a premium, and as long there is sufficient supply of arrestin, but it is unfavourable when the light levels drop and a high sensitivity is required. Insect photoreceptors, therefore, have additional mechanism to regenerate their rhodopsin content.

Visual pigment turnover and regeneration

Regeneration of invertebrate visual pigment by means other than by photoreconversion of metarhodopsin was experimentally shown decades ago (octopus, Schwemer 1969; blowfly, Stavenga et al. 1973; butterfly, Stavenga 1975; Bernard 1983a, b) and was demonstrated to be due to turnover of visual pigment (Stein et al. 1978; Schwemer 1979). Similar processes appear to exist universally in invertebrate eyes (Goldsmith and Bernard 1985). Schwemer (1984), in an extensive series of experiments on blowfly eyes, revealed the pathway of visual pigment turnover and renewal, which involves light-dependent enzymatic processes in the pigment cells (review
Schwemer 1989, 1993). Nevertheless, even until recently it appears to have been widely 'thought that photoreceptor cells in invertebrates such as Drosophila do not employ enzymes for chromophore regeneration' (Wang et al. 2010; Arshavsky 2010; von Lintig et al. 2010). Unfortunately, the recognition that invertebrates have bistable visual pigments together with the early demonstration that blowfly eyes are red pigmented to photoreconvert metarhodopsin (Stavenga et al. 1973) has become elevated to 'the dogma that the visual cycle in invertebrates does not exist' (Arshavsky 2010). Consequently the recent characterization of a retinol dehydrogenase required for chromophore regeneration in Drosophila was heralded as the first demonstration of a chromophore regeneration pathway in non-vertebrate species (Wang et al. 2010; Arshavsky 2010; von Lintig et al. 2010). In fact, Wang et al.'s (2010) characterization of a fly retinol dehydrogenase represents welcome new molecular insight into a pathway first recognized over 30 years ago. Unlike the vertebrate chromophore recycling pathway, however, the invertebrate chromophore regeneration pathway is light dependent and the isomerization of all-trans to 11-cis retinal is mediated by a photoisomerase activated by blue light $\left(\lambda_{\max }=420 \mathrm{~nm}\right)$. The molecular identity of the photoisomerase in Drosophila and other insects remains unknown, although it has been purified from bee retina (Schwemer et al. 1984; Smith and Goldsmith 1991a), and what may be the equivalent enzyme (retinochrome) has been cloned and sequenced from squid (Hara-Nishimura et al. 1990). Whereas in cephalopods the photoisomerase is located inside the photoreceptors, in the eyes of insects, like the honeybee, it is mainly positioned in the pigment cells (Smith and Goldsmith 1991b). This allows usage of incident light that would otherwise be absorbed by the screening pigments. Flies apply the same system (Schwemer 1989, 1993), and have realized another degree of sophisticated use of waste-light by making the screening pigments red transparent in combination with a blue-greenabsorbing rhodopsin and a strongly bathochromic shifted, orange-absorbing metarhodopsin.

The speed of the turnover processes differs widely between species. The metarhodopsin of R1-6 photoreceptors decays exponentially with a half-time of about $2 \mathrm{~h}$ in blowflies (Schwemer 1984) and $\sim 13 \mathrm{~h}$ in Drosophila (Hofstee 1996). Rhodopsin regeneration occurs upon injection of 11-cis retinal, but also by simply returning the animals to room light (blowfly, half-time $9 \mathrm{~h}$; Schwemer 1984), demonstrating that the released all-trans chromophore is isomerized by a light-driven enzymatic process (Schwemer 1989). Blue (420 nm) light-driven regeneration of 11-cis retinal described in fruitflies is again somewhat slower with a half-time greater than $24 \mathrm{~h}$ (Isono et al. 1988), consistent with the slow regeneration described by Wang et al. (2010). Visual pigment turnover in butterflies 
is much faster. The blue-absorbing metarhodopsins belonging to the green-absorbing rhodopsins decay with an exponential time course that strongly depends on temperature: at $12.5,23.0$ and $26.5^{\circ} \mathrm{C}$ the decay half-time was assessed at about 50,12 and $3 \mathrm{~min}$, respectively (Bernard 1983b). The slower rhodopsin regeneration (half time at room temperature about $40 \mathrm{~min}$; Vanhoutte and Stavenga, 2005) was found to be complex and dependent on the illumination history (Bernard 1983b). The experimental values obtained from butterflies dictated the time constants of visual pigment decay and regeneration $(3$ and $10 \mathrm{~min}$, respectively) used in the calculations of Fig. $7 b, d$, f. In the "Results" we have assumed that the turnover processes of the green rhodopsin of bees have temporal characteristics similar to those of the butterflies.

During flight larger insects can reach body temperatures that are distinctly higher than the ambient temperature, due to the heat generated by the flight muscles. The head of honeybees can reach temperatures well above $40^{\circ} \mathrm{C}$ (Heinrich 1993). Accordingly, it can be expected that metarhodopsin decay as well as rhodopsin regeneration will be very fast. This will be especially welcome for the green sensitive photoreceptors; firstly to rapidly reduce the amount of metarhodopsin and secondly to increase the rhodopsin level. A speedy visual pigment turnover will be less necessary for blowfly photoreceptors, because their metarhodopsin is already kept within bounds by alternative, photochemical methods. Although the temperature of blowfly heads is also elevated during flight (Stavenga et al. 1993), the much slower visual pigment turnover presumably is related to their very different photochemical system.

\section{The visual pigment-arrestin cycle}

The visual pigment-arrestin cycle of Fig. 5 served to gain a semi-quantitative understanding of how visual pigment molecules are distributed over the different possible states and their coupling to arrestin as a function of light intensity. The parameters used to calculate the intensity dependence pictured in Figs. 6 and 7 are estimates based largely on studies on Drosophila R1-6 photoreceptors, and they may well be rather different for the green receptors, which make up the majority of insect photoreceptors. Nevertheless, the general trends shown in Figs. 6 and 7 are probably adequate for understanding the distribution of the visual pigment over the various states. For example, only a minor fraction of the visual pigment molecules will exist in the active metarhodopsin state $\left(\mathrm{M}_{\mathrm{a}}\right)$, the trigger of the phototransduction process. Over most of the physiological range of light intensities $M_{a}$ is proportional to the light intensity, and only at very high light levels beyond the normal physiological range there will be more than one active metarhodopsin per microvillus, which is likely to saturate the electrophysiological response of the photoreceptors.

Fly photoreceptors with total metarhodopsin fractions in the order of 0.2 , that is 200 metarhodopsin molecules per microvillus, in principle can manage with a few hundred arrestin molecules per microvillus to avoid the PDA-danger zone. Indeed, Drosophila photoreceptors in the lightadapted state accumulate $\sim 370$ arrestins per microvillus (Satoh et al. 2010), and when $f_{\mathrm{Me}}$ is low $(<0.1)$ most of these translocate out of the rhabdomeres, leaving only about 90 arrestins per microvillus, presumably to increase the photoreceptor's integration time and thus its light sensitivity (Liu et al. 2008; Satoh et al. 2010). When $f_{\mathrm{Me}}$ exceeds $\sim 0.35$ (only found under experimental conditions), the supply of arrestin is exhausted, $\mathrm{M}_{\mathrm{a}}$ persists indefinitely and a PDA is maintained even in the dark for many hours. For stimuli generating intermediate metarhodopsin fractions $\left(f_{\mathrm{Me}}=0.1-0.35\right)$, there is a short-lived PDA, which decays with a time course reflecting the time course of translocation (Satoh et al. 2010).

Blowfly photoreceptors also exhibit a PDA with blue light; however, even with a maximal metarhodopsin fraction of $\sim 0.7$, this decays to baseline over a few minutes (Hamdorf and Razmjoo 1977; Hamdorf 1979; Hamdorf and Razmjoo 1979; Razmjoo and Hamdorf 1980; review Hillman et al. 1983). The reason for this distinction between the PDA of blowfly and fruitfly has never been satisfactorily explained. We suggest the absence of a long lasting PDA in blowflies may reflect a higher absolute level of arrestin, probably equivalent to $>800$ arrestin molecules per microvillus (cf. Fig. 6b, d, f), and that the decaying PDA reflects the time course of translocation. Thus, if, as in Drosophila, only $\sim 25 \%$ of the arrestin is present in the dark-adapted rhabdomere, a PDA will result in response to stimuli generating $M_{\mathrm{a}}$ in excess of say, 200. However, the PDA then decays as the remaining arrestin translocates into the rhabdomere. Interestingly this interpretation of the Calliphora PDA also has the potential to account for the "anti-PDA"-a mysterious and unexplained phenomenon first described over 30 years ago. Namely, following the decay of the PDA and reconversion of $\mathrm{M}$ to $\mathrm{R}$ a further PDA (by R to M conversion) can only be elicited if the photoreceptor is first left for some time $(\sim 10 \mathrm{~s})$ in the dark (review: Hillman et al. 1983). On this interpretation, the anti-PDA (i.e. the inability to induce a second PDA) arises because the rhabdomere is fully loaded with arrestin following translocation, and how long it lasts will depend upon the time course of the reverse translocation of arrestin out of the rhabdomere.

We suggest that the reason why fast flying blowflies may have higher arrestin levels than Drosophila, is that they require photoreceptors with a short integration time 
and thus a high amount of arrestin to rapidly quench a rhodopsin molecule after its photoconversion into the active metarhodopsin state, resulting in a short-lived photon signal, the bump.

For green receptors, broad-band, natural illuminations generate metarhodopsin fractions $>0.6$ at high intensities. Nevertheless, because of metarhodopsin degradation, our model predicts that there may be a maximal requirement for only ca 200 arrestin molecules at highest light intensities (Fig. 7d). However, this is under steady-state conditions, and the situation would be different for a darkadapted photoreceptor with fully regenerated rhodopsin suddenly exposed to daylight conditions (as might occur when a honeybee leaves its hive). To prevent a PDA under such conditions, it would seem essential to have approximately as many arrestin molecules as rhodopsin. To our knowledge, estimates of arrestin levels in insects other than Drosophila are not available. As we suggest for the blowfly, we predict that the absolute levels of arrestin in the green photoreceptors of the majority of insects are likely to be at least $80 \%$ of the number of rhodopsin molecules.

Because of the rapid metarhodopsin decay and slower rhodopsin regeneration in the green receptors, the visual pigment level, and thus photosensitivity, will decrease during continuous illumination (Fig. 7f). We suggest that this may be turned to advantage as a mechanism of light adaptation, reducing sensitivity and extending the dynamic range. A similar sensitivity control by bleaching of visual pigment at very bright light levels is believed to play a crucial role in light adaptation in vertebrate cone photoreceptors (Burkhardt 1994; Mata et al. 2002; Ala-Laurila et al. 2006; review, Pugh et al. 1999).

Acknowledgments We thank Drs Gregor Belušič and Kentaro Arikawa for reading the manuscript and providing valuable suggestions. Financial support was given by AFOSR/EOARD grant no. FA8655-08-1-3012 (to DGS) and by the BBSRC (to RCH).

Open Access This article is distributed under the terms of the Creative Commons Attribution Noncommercial License which permits any noncommercial use, distribution, and reproduction in any medium, provided the original author(s) and source are credited.

\section{Appendix}

The visual pigment-arrestin cycle

In the visual pigment-arrestin cycle of Fig. $5, R_{\mathrm{a}}\left(R_{\mathrm{i}}\right)$ and $M_{\mathrm{a}}\left(M_{\mathrm{i}}\right)$ are the (in)active rhodopsin and metarhodopsin states. The light-induced conversion processes have rate constants $k_{\mathrm{R}}$ and $k_{\mathrm{M}}$, and the binding and dissociation rate constants of arrestin, $\mathrm{A}$, are $k_{\mathrm{b}}$ and $k_{\mathrm{d}} . R_{\mathrm{i}}$ and $M_{\mathrm{i}}$ decay with rate constant $k_{\mathrm{f}}$, and $R_{\mathrm{a}}$ is regenerated with rate constant $k_{\mathrm{g}}$. In the calculations of Figs. 6 and 7, we consider one microvillus with total number of visual pigment molecules.

$R_{0}=R_{\mathrm{a}}+M_{\mathrm{a}}+R_{\mathrm{i}}+M_{\mathrm{i}}$

If the microvillus is not completely filled with the maximal number of molecules $R_{\max }$ then the number of missing visual pigment molecules is $R_{\mathrm{m}}=R_{\max }-R_{0}$. When $A_{0}$ is the total number of arrestin molecules and $A$ the number of unbound arrestin molecules, then

$A_{0}=R_{\mathrm{i}}+A+M_{\mathrm{i}}$

The rhodopsin-arrestin cycle is described by a set of linear differential equations:

$\mathrm{d} R_{\mathrm{a}} / \mathrm{d} t=-k_{\mathrm{R}} R_{\mathrm{a}}+k_{\mathrm{M}} M_{\mathrm{a}}+k_{\mathrm{g}} R_{\mathrm{m}}$

$\mathrm{d} M_{\mathrm{a}} / \mathrm{d} t=-k_{\mathrm{M}} M_{\mathrm{a}}+k_{\mathrm{R}} R_{\mathrm{a}}-k_{\mathrm{b}} A M_{\mathrm{a}}$

$\mathrm{d} M_{\mathrm{i}} / \mathrm{d} t=-k_{\mathrm{M}} M_{\mathrm{i}}+k_{\mathrm{R}} R_{\mathrm{i}}+k_{\mathrm{b}} A M_{\mathrm{a}}-k_{\mathrm{f}} M_{\mathrm{i}}$

$\mathrm{d} R_{\mathrm{i}} / \mathrm{d} t=-k_{\mathrm{R}} R_{\mathrm{i}}+k_{\mathrm{M}} M_{\mathrm{i}}-k_{\mathrm{d}} R_{\mathrm{i}}-k_{\mathrm{f}} R_{\mathrm{i}}$

$\mathrm{d} A / \mathrm{d} t=-k_{\mathrm{b}} A M_{\mathrm{a}}+k_{\mathrm{d}} R_{\mathrm{i}}+k_{\mathrm{f}} M_{\mathrm{i}}+k_{\mathrm{f}} R_{\mathrm{i}}$

In the steady state $\mathrm{d} R_{\mathrm{a}} / \mathrm{d} t=\mathrm{d} M_{\mathrm{a}} / \mathrm{d} t=\mathrm{d} M_{\mathrm{i}} / \mathrm{d} t=$ $\mathrm{d} R_{\mathrm{i}} / \mathrm{d} t=\mathrm{d} A / \mathrm{d} t=0$. The fraction of metarhodopsin in equilibrium is

$f_{\mathrm{Me}}=\left(M_{\mathrm{a}}+M_{\mathrm{i}}\right) / R_{0}$

Equation 10 is equivalent to Eq. 2 when visual pigment turnover is negligible, i.e. $k_{\mathrm{g}}, k_{\mathrm{f}} \ll k_{\mathrm{R}}, k_{\mathrm{M}}$ (see Fig. 7).

\section{References}

Ala-Laurila P, Kolesnikov AV, Crouch RK, Tsina E, Shukolyukov SA, Govardovskii VI, Koutalos Y, Wiggert B, Estevez ME, Cornwall MC (2006) Visual cycle: dependence of retinol production and removal on photoproduct decay and cell morphology. J Gen Physiol 128:153-169

Arshavsky VY (2010) Vision: the retinoid cycle in Drosophila. Curr Biol 20:R96-R98

Belušič G, Pirih P, Stavenga DG (2010) Photoreceptor responses of fruitflies with normal and reduced arrestin content studied by simultaneous measurements of visual pigment fluorescence and ERG. J Comp Physiol A 196:23-35

Bernard GD (1983a) Bleaching of rhabdoms in eyes of intact butterflies. Science 219:69-71

Bernard GD (1983b) Dark-processes following photoconversion of butterfly rhodopsins. Biophys Struct Mech 9:227-286

Briscoe AD, Chittka L (2001) The evolution of color vision in insects. Annu Rev Entomol 46:471-510

Briscoe AD, Bernard GD, Szeto AS, Nagy LM, White RH (2003) Not all butterfly eyes are created equal: Rhodopsin absorption spectra, molecular identification, and localization of ultraviolet-, blue-, and green-sensitive rhodopsin-encoding mRNAs in the retina of Vanessa cardui. J Comp Neurol 458:334-349

Burkhardt DA (1994) Light adaptation and photopigment bleaching in cone photoreceptors in situ in the retina of the turtle. J Neurosci 14:1091-1105 
Dartnall HJA (1972) Photosensitivity. In: Dartnall HJA (ed) Handbook of sensory physiology, vol VII/1. Spinger, Berlin, pp 122-145

Dolph PJ, Ranganathan R, Colley NJ, Hardy RW, Socolich M, Zuker CS (1993) Arrestin function in inactivation of G protein-coupled receptor rhodopsin in vivo. Science 260:1910-1916

Franceschini N (1975) Sampling of the visual environment by the compound eye of the fly: fundamentals and applications. In: Snyder AW, Menzel R (eds) Photoreceptor optics. Springer, Berlin, pp 98-125

Franceschini N, Kirschfeld K (1976) Le contrôle automatique du flux lumineux dans l'oeil composé des Diptéres. Propriétés spectrales, statiques et dynamiques du mécanisme. Biol Cybern 21:181-203

Goldsmith TH, Bernard GD (1985) Visual pigments of invertebrates. Photochem Photobiol 42:805-809

Hamdorf K (1979) The physiology of invertebrate visual pigments. In: Autrum H (ed) Handbook of sensory physiology, vol VII/6A. Springer, Berlin, pp 145-224

Hamdorf K, Razmjoo S (1977) The prolonged depolarizing afterpotential and its contribution to the understanding of photoreceptor function. Biophys Struct Mech 3:163-170

Hamdorf K, Razmjoo S (1979) Photoconvertible pigment states and excitation in Calliphora; the induction and properties of the prolonged depolarizing afterpotential. Biophys Struct Mech 5:137-161

Hara-Nishimura I, Matsumoto T, Mori H, Nishimura M, Hara H, Hara $\mathrm{T}$ (1990) Cloning and nucleotide sequence of cDNA for retinochrome, retinal photoisomerase from the squid retina. FEBS Letters 271:106-110

Hardie RC, Postma M (2008) Phototransduction in microvillar photoreceptors of Drosophila and other invertebrates. In: Basbaum AI et al (eds) The senses: A comprehensive reference, vol 1, Vision I. Academic Press, San Diego, pp 77-130

Heinrich B (1993) The hot-blooded insects, strategies and mechanisms of thermoregulation. Springer, Berlin

Hillman P, Hochstein S, Minke B (1983) Transduction in invertebrate photoreceptors: role of pigment bistability. Physiol Rev 63:668-772

Hofstee CA (1996) The $\mathrm{Ca}^{2+}$ homeostasis of the photoreceptor cell of Drosophila studied with the pupil mechanism. Thesis, University of Groningen

Isono K, Tanimura T, Oda Y, Tsukahara Y (1988) Dependency on light and vitamin A derivatives of the biogenesis of 3-hydroxyretinal and visual pigment in the compound eyes of Drosophila melanogaster. J Gen Physiol 92:587-600

Katz B, Minke B (2009) Drosophila photoreceptors and signaling mechanisms. Front Cell Neurosci 3:2

Langer H (1975) Properties of screening pigments in insect eyes. In: Snyder AW, Menzel R (eds) Photoreceptor optics. Springer, Berlin, pp 429-455

Langer H, Struwe G (1972) Spectral absorption by screening pigment granules in the compound eye of butterflies (Heliconius). J Comp Physiol 79:203-212

Liu CH, Satoh AK, Postma M, Huang J, Ready DF, Hardie RC (2008) $\mathrm{Ca}^{2+}$-dependent metarhodopsin inactivation mediated by calmodulin and NINAC myosin III. Neuron 59:778-789

Mata NL, Radu RA, Clemmons RS, Travis GH (2002) Isomerization and oxidation of vitamin a in cone-dominant retinas: a novel pathway for visual-pigment regeneration in daylight. Neuron 36:69-80

McFarland WN, Munz RW (1976) The visible spectrum during twilight and its implications to vision. In: Evans GC, Bainbridge $\mathrm{R}$, Rackham $\mathrm{O}$ (eds) Light as an ecological factor, vol II. Blackwell, Oxford, pp 249-270
Menzel R (1979) Spectral sensitivity and color vision in invertebrates. In: Autrum H (ed) Handbook of sensory physiology Vol VII/6A. Springer, Berlin, pp 503-580

Minke B, Wu CF, Pak WL (1975) Isolation of light-induced response of the central retinula cells from the electroretinogram of Drosophila. J Comp Physiol 98:345-355

Peitsch D, Fietz A, Hertel H, de Souza J, Ventura DF, Menzel R (1992) The spectral input systems of hymenopteran insects and their receptor-based colour vision. J Comp Physiol A 170:23-40

Plangger A, Malicki D, Whitney M, Paulsen R (1994) Mechanism of arrestin 2 function in rhabdomeric photoreceptors. J Biol Chem 269:26969-26975

Pugh EN Jr, Nikonov S, Lamb TD (1999) Molecular mechanisms of vertebrate photoreceptor light adaptation. Curr Opin Neurobiol 9:410-418

Razmjoo S, Hamdorf K (1980) In support of the "photopigment model" of vision in invertebrates. J Comp Physiol 135:209-215

Roebroek JGH, Stavenga DG (1990a) On the effective density of the pupil mechanism of fly photoreceptors. Vision Res 30:1235-1242

Roebroek JGH, Stavenga DG (1990b) Insect pupil mechanisms. IV. Spectral characteristics and light intensity dependence in the blowfly, Calliphora erythrocephala. J Comp Physiol A 166:537-543

Saari JC (2000) Biochemistry of visual pigment regeneration. The Friedenwald lecture. Invest Ophthalmol Vis Sci 41:337-348

Salcedo E, Huber A, Henrich S, Chadwell LV, Chou WH, Paulsen R, Britt SG (1999) Blue- and green-absorbing visual pigments of Drosophila: ectopic expression and physiological characterization of the R8 photoreceptor cell-specific Rh5 and Rh6 rhodopsins. J Neurosci 19:10716-10726

Satoh AK, Xia H, Yan L, Hardie RC, Ready DF (2010) Arrestin translocation is stoichiometric to rhodopsin isomerization and accelerated by phototransduction in Drosophila photoreceptors. Neuron 67:997-1008

Schwemer J (1969) Der Sehfarbstoff von Eledone moschata und seine Umsetzungen in der lebenden Netzhaut. Z Vgl Physiol $62: 121-152$

Schwemer J (1979) Molekulare Grundlagen der Photorezeption bei der Schmeissfliege Calliphora erythrocephala Meig. Habilitationsschrift, Bochum

Schwemer J (1984) Renewal of visual pigment in photoreceptors of the blowfly. J Comp Physiol A 154:535-547

Schwemer J (1989) Visual pigments of compound eyes-structure, photochemistry, and regeneration. In: Stavenga DG, Hardie RC (eds) Facets of vision. Springer, Berlin, pp 112-133

Schwemer J (1993) Visual pigment renewal and the cycle of the chromophore in the compound eye of the blowfly. In: Wiese K, Gribakin F, Popov AV, Renninger G (eds) Sensory systems of arthropods. Birkhäuser Verlag, Basel, pp 54-68

Schwemer J, Pepe IM, Paulsen R, Cugnoli C (1984) Light-induced trans-cis isomerization of retinal by a protein from honeybee retina. J Comp Physiol A 154:549-554

Smith WC, Goldsmith TH (1991a) The role of retinal photoisomerase in the visual cycle of the honeybee. J Gen Physiol 97:143-165

Smith WC, Goldsmith TH (1991b) Localization of retinal photoisomerase in the compound eye of the honeybee. Vis Neurosci 7:237-249

Stavenga DG (1975) Dark regeneration of invertebrate visual pigments. In: Snyder AW, Menzel R (eds) Photoreceptor optics. Springer, Berlin, pp 126-144

Stavenga DG (1980) Short wavelength light in invertebrate visual sense cells. Pigments, potentials and problems. In: Senger H (ed) The blue light syndrome. Springer, Berlin, pp 5-24

Stavenga DG (1995) Insect retinal pigments. Spectral characteristics and physiological functions. In: Osborne NN, Chader GJ (eds) 
Progress in retinal and eye research, vol 15. Pergamon Press, pp 231-259

Stavenga DG (2002) Colour in the eyes of insects. J Comp Physiol A 188:337-348

Stavenga DG (2003) Angular and spectral sensitivity of fly photoreceptors. II. Dependence on facet lens F-number and rhabdomere type in Drosophila. J Comp Physiol A 189:189-202

Stavenga DG (2004) Angular and spectral sensitivity of fly photoreceptors. III. Dependence on the pupil mechanism in the blowfly Calliphora. J Comp Physiol A 190:115-129

Stavenga DG (2010) On visual pigment templates and the spectral shape of invertebrate rhodopsins and metarhodopsins. J Comp Physiol A 196:869-878

Stavenga DG, Kuiper JW (1977) Insect pupil mechanisms. I. On the pigment migration in the retinula cells of Hymenoptera (suborder Apocrita). J Comp Physiol A 113:55-72

Stavenga DG, Schwemer J (1984) Visual pigments of invertebrates. In: Ali MA (ed) Photoreception and vision of invertebrates. Plenum, New York, pp 11-61

Stavenga DG, Zantema A, Kuiper JW (1973) Rhodopsin processes and the function of the pupil mechanism in flies. In: Langer $\mathrm{H}$ (ed) Biochemistry and physiology of visual pigments. Springer, Berlin, pp 175-180

Stavenga DG, Schwering P, Tinbergen J (1993) A 3-compartment model describing temperature-changes in tethered flying blowflies. J Exp Biol 185:325-333

Stavenga DG, Oberwinkler J, Postma M (2000) Modeling primary visual processes in insect photoreceptors. In: Stavenga DG, DeGrip WJ, Pugh EN Jr (eds) Molecular mechanisms in visual transduction. Handbook of biological physics, vol 3. Elsevier, Amsterdam, pp 527-574
Stein PJ, Brammer JO, Ostroy SE (1978) Renewal of opsin in the photoreceptor cells of the mosquito. J Gen Physiol 74:565-582

Strother GK, Casella AJ (1972) Microspectrophotometry of arthropod visual screening pigments. J Gen Physiol 59:616-636

Vanhoutte KJA, Stavenga DG (2005) Visual pigment spectra of the comma butterfly, Polygonia c-album, derived from in vivo epiillumination. J Comp Physiol A 191:461-473

Vinós J, Jalink K, Hardy RW, Britt SG, Zuker CS (1997) A G proteincoupled receptor phosphatase required for rhodopsin function. Science 277:687-690

von Lintig J, Kiser PD, Golczak M, Palczewski K (2010) The biochemical and structural basis for trans-to-cis isomerization of retinoids in the chemistry of vision. Trends Biochem Sci 35:400-4010

Wakakuwa M, Stavenga DG, Arikawa K (2007) Spectral organization of ommatidia in flower-visiting insects. Photochem Photobiol $83: 27-34$

Wang T, Montell C (2007) Phototransduction and retinal degeneration in Drosophila. Pflügers Arch. 454:821-847

Wang XY, Wang T, Jiao YC, von Lintig J, Montell C (2010) Requirement for an enzymatic visual cycle in Drosophila. Curr Biol 20:93-102

Warrant EJ, Nilsson DE (1998) Absorption of white light in photoreceptors. Vision Res 38:195-207

Yau KW, Hardie RC (2009) Phototransduction motifs and variations. Cell 139:246-264

Zaccardi G, Kelber A, Sison-Mangus MP, Briscoe AD (2006) Color discrimination in the red range with only one long-wavelength sensitive opsin. J Exp Biol 209:1944-1955 